\title{
НОВЫЕ ПРАВИЛА СОСТАВЛЕНИЯ ЗАЯВОК НА ИЗОБРЕТЕНИЯ
}

\section{NEW RULES FOR SUBMISSION OF APPLICATIONS FOR INVENTIONS}

\author{
Д.Ю.Соколов, главный конструктор ООО "СНОТРА", (ORCID 0000-0002-2860-996) / sokolovdmi@mail.ru \\ D.Yu.Sokolov, General Constructor JSC "SNOTRA"
}

DOI: 10.22184/1993-8578.2019.12.1.60.63

Получено: 31.01 .2019 г.

В статье рассмотрены изменения в правилах по составлению заявок на изобретения, отмечено, что упростило, а что усложнило эти работы, а также показано, как решать новые проблемы.

The article discusses the changes in the rules for the preparation of applications for inventions, noted that it simplified, complicated this work, and also showed how to solve new problems.

Д о 24 мая 2016 года в Российской Федерации действовал "Административный регламент исполнения Федеральной службой по интеллектуальной собственности, патентам и товарным знакам государственной функции по организации приема заявок на изобретение и их рассмотрения, экспертизы и выдачи в установленном порядке патентов Российской Федерации на изобретение", утвержденный приказом Министерства образования и науки Российской Федерации от 29 октября 2008 года № 327" (далее Регламент). Критика и рекомендации по его использованию были подробно рассмотрены в [1]. В настоящее время действуют "Правила составления, подачи и рассмотрения документов, являющихся основанием для совершения юридически значимых действий по государственной регистрации изобретений и их формы", утвержденные приказом Минэкономразвития России от 25 мая 2016 года № 316 (далее - Правила). Эти Правила во многом повторяют отмененный Регламент. Некоторые положения Правил упростили понимание Регламента и подготовку заявок на изобретения, но, к сожалению, отдельные недостатки Регламента перешли в новые Правила и даже усугубились. Рассмотрим подробно наиболее важные положения Правил, касающиеся составления заявок на изобретения.

С п.1 по п. 13 выделены "Общие требования к оформлению заявок". В них более определенно выделены требования соблюдать "...единство терминологии, то есть одни и те же признаки изобретения в описании изобретения и в формуле изобретения должны быть названы одинаково" (п. 6). Это очень важное требование, и для рассмотрения заявки в Федеральном институте промышленной собственности (далее - ФИПСе) и для ее понимания, но оно почти всегда нарушается изобретателями. Также важно на первый взгляд несущественное требование п. 9- печатать текст через 1,5 интервала. Это связано с тем, что при корректировке текста заявки эксперту нужно свободное место между строчками, чтобы вписывать туда исправления, что упрощает его работу.

В п. п. 14-29 изложены требования к заявлению о выдаче патента. Эти требования касаются нового бланка заявления, который можно найти на сайте ФИПСа (http://wwwl.fips.ru/) по ссылке "изобретения и полезные модели - образцы заявлений", и изложены они достаточно понятно. Единственное, что следует отметить, это простановка знака "X" (п. 20, $24,25)$ в соответствующих клетках бланка. Если программное обеспечение компьютера не позволяет ставить эти значки (что случается), то их можно проставлять, например, карандашом по линейке.

Начиная с п. 30 по п. 51 раскрываются "Требования к описанию изобретения". В п. 30 приведена структура описания и перечислены его разделы. Основными из них являются:

- область техники, к которой относится изобретение;

- уровень техники;

- раскрытие сущности изобретения;

- краткое описание чертежей;

- осуществление изобретения. 
Эта структура заявки существует уже более 100 лет. За основу ее была взята немецкая структура, как наиболее упорядоченная для своего времени.

Начинается описание с индекса изобретения, который ставится в правом верхнем углу и который бывает достаточно скопировать из одного из аналогов (патентов) предложенного изобретения. Далее следует название изобретения, требования к которому подробно изложены в п. 33 Правил. И сразу же в п. 33. 1 следует нововведение, которое обязывает указывать в названии назначение изобретения, в отличие от Регламента, в котором говорилось, что "название изобретения, как правило, характеризует его назначение". И если до 2016 года названия были часто излишне информативны, то сейчас это может только усугубиться. А слишком подробное название часто невольно искажает сущность изобретения, сужая при этом его область применения. Часто разработчики, занимаясь узкой проблемой, переносят ее в название изобретения, не задумываясь о возможности более широкого его использования. Например, был разработан оптический микроскоп для исследования биологических объектов. Не всегда в названии надо это конкретизировать, и часто название может быть просто "Оптический микроскоп", особенно если он годится и для исследования иных объектов.

А вот в п. 34 "Область техники, к которой относится изобретение", уже можно написать, что "оптический микроскоп предназначен преимущественно для исследования биологических объектов". И не помешает поискать и указать его более широкое использование.

Пункт 35 "Уровень техники" упростил, но при этом конкретизировал задачу изобретателю. Если раньше в этом разделе необходимо было приводить "сведения об известных заявителю аналогах", то сейчас действует уточнение, что "приводятся сведения из предшествующего уровня техники, необходимые для понимания сущности изобретения, проведения информационного поиска и экспертизы заявки...". Из Регламента следовало, что заявитель должен был приводить все известные ему аналоги, а упростившийся патентный поиск позволяет находить их сотнями. И действительно, часто уровень техники описывался десятками патентов. А согласно Правилам, количество анализируемых патентов может быть уменьшено, например, до двух-трех аналогов, но качество анализируемых патентов должно быть выше, чтобы была разъяснена сущность изобретения и выполнены другие требования (см. выше п. 36).
И, наконец, мы подошли п. 36 "Раскрытие сущности изобретения", самому спорному разделу Правил.

Основные проблемы, возникающие при использовании отмененного Регламента, были связаны именно с этим разделом. Как я уже отмечал, в российской патентной практике в начале прошлого века за основу была взята немецкая структура заявки. Рациональные немцы решили, что для быстроты восприятия технической информации в общем виде целесообразно в начале заявки простым языком изложить сущность изобретения. При этом на начальном этапе ознакомления с патентом не нужно вникать в юридический язык формулы изобретения, разбираться в чертежах, знакомиться с особенностями раскрытия отличительных признаков изобретения. Сто лет назад это было верное решение. Примерно до 1970-х годов во всем мире изобретения в основной своей массе были относительно просты и, действительно, в нескольких предложениях можно было объяснить их сущность. Для примера можно посмотреть почти любое японское изобретение 1960-х годов и сравнить его с современным японским патентом. Разница в сложности может достигать 2-х порядков. Близкая картина и в патентных практиках других стран. Современные изобретения могут включать десятки чертежей, с сотнями элементов. Формулы изобретения могут также содержать сотни отличительных признаков. И в настоящее время до описания чертежей, до раскрытия особенностей осуществления изобретения с упоминанием основных позиций чертежей изложить сущность изобретения бывает практически невозможно. Хотя многие изобретатели это делать пытаются. Если человек лет десять работал над одной проблемой, он сделать это сможет, как ему кажется. Всем другим понять этот текст будет невозможно. Как решить эту проблему с учетом новых Правил? Борьба с требованиями к этому разделу старого Регламента подробно рассмотрена в приведенной выше литературе. Теперь рассмотрим изменения, изложенные в новых Правилах.

В п. 36.1 в разделе "Раскрытие сущности изобретения" указано, что "должны быть раскрыты все существенные признаки изобретения". В Регламенте было сказано, что "приводятся все существенные признаки...". В дополнение к этому в п. 37.1 Правил указано, что при раскрытии сущности изобретения, относящегося к устройству, необходимо указывать особенности конструктивного исполнения: количество деталей, методы их соединения, взаимное расположение и материалы. Представьте 
себе, вы еще не дошли до раскрытия чертежей, а от вас уже требуют описать конструкцию словесно без указания ссылок на позиции чертежей. Причем этих ссылок иногда, как уже было сказано, бывает больше сотни. Многие изобретатели безуспешно пытались подобное делать и ранее, выполняя Регламент, а сейчас в необходимости этой работы их дополнительно убеждает словосочетание "должны быть раскрыты" новых Правил. Как решать эту проблему согласно старому Регламенту я уже подробно раскрывал в [1]. Надеюсь, что по новым Правилам поступать можно будет также. А именно, излагать формулу изобретения своими словами в виде отдельных предложений. Я надеюсь, что составители новых Правил не будут требовать большего, а словосочетание "должны быть раскрыты" можно будет трактовать, как просто перечисление признаков, изложенных в формуле изобретения. Это косвенно подтверждается п. 37.2, где упоминается формула изобретения с характеристикой изложения признаков в статическом состоянии, что абсолютно верно.

Несколько облегчает работу изобретателя то, что из раздела Сущность изобретения исключено требование "определить задачу изобретения", что, по сути, часто дословно является техническим результатом. И ранее приходилось долго "ломать голову", как бы выразить технический результат и задачу изобретения разными словами. А вот исключение из Регламента положения о том, что можно менять порядок изложения для лучшего понимания заявки приведет к двойственному результату. С одной стороны, этот порядок (п. 30) нужно соблюдать, с другой - исключается возможность в особо сложных заявках частично раскрытие сущности изобретения перемещать в раздел "Осуществление изобретения".

Пункт 44 "Краткое описание чертежей" остался неизменным, но хочется подчеркнуть, что выполняя требование "краткого пояснения, что изображено на каждом из них" вполне достаточно указать только наименование изображения, например: "На рис.1 изображена компоновочная схема координатного стола в общем виде", не указывая его состава.

В п. 45 "Осуществление изобретения" более определенно рекомендуется использовать графические материалы для детального описания примеров. До сих пор достаточно часто, например, способы пытаются запатентовать без приведения графических материалов. Но почти всегда способы реализуются с использованием устройств и инструментов. И если изобретателю может быть понятно описание способа без графических материалов, то и эксперту и, часто, специалисту, разобраться в этом бывает достаточно сложно. Поэтому, даже в способах до раскрытия пункта "Осуществление изобретения" часто бывает целесообразно приводить хотя бы упрощенные описания устройств, используемых для реализации способа. В п. 45.4 указано на то, что "если изобретение охарактеризовано в формуле изобретения количественными существенными признаками, выраженными в виде интервала непрерывно изменяющихся значений параметра, должны быть приведены примеры осуществления изобретения, показывающие возможность получения технического результата во всем этом интервале". Аналогичное требование было в предыдущем регламенте. Оно трудновыполнимо из-за того, что требует приводить много примеров. Дополнение его определением "непрерывно" никак не облегчает задачу изобретателю. Хотя есть и послабление, связанное с указанием на то, что для подтверждения технического результата допустимо приводить "...теоретические обоснования, основанные на научных знаниях".

В п. 46. 2 внесено дополнение о том, что "при использовании в устройстве новых материалов описывается способ их получения". Это дополнение уместно, так как одно из условий патентоспособности технического решения является его "промышленная применимость". Тем не менее здесь надо иметь в виду, что если материалы действительно новые, то они могут быть запатентованы в виде веществ или способов. В П. 46.4 внесено дополнение, касающееся возможности внесения в описание кратких выдержек из программ "на используемых языках программирования". Данное дополнение "легализует" косвенную патентную защиту программ через патентование устройств и способов, непосредственно с ними связанных, что давно уже используется на практике.

В п. 49.1 указано аналогичное требование при патентовании способов. "При использовании неизвестных средств (например, устройств, веществ...) приводятся сведения, позволяющие их осуществить, и в случае необходимости прилагается графическое изображение". В данном случае возможен, а часто и целесообразен вариант одновременного патентования способа и устройства или способа и вещества в виде многозвенной формулы изобретения с двумя независимыми пунктами.

Начиная с п. 52 по п. 55 изложены "Требования к формуле изобретения". По сути, изменений в этих требованиях немного. Тем не менее хочется остановиться на нескольких положениях. В п. 53. 3 сказано, 
что "формула изобретения должна быть полностью основана на описании...". С этим трудно не согласиться, но изобретатели часто берут это положение как руководство к действию по составлению заявок. То есть, сначала подготавливают текст описания, а потом формулу изобретения. Но в большинстве случаев это абсолютно неверно. Дело в том, что формула изобретения, по сути, повторяется в описании пять раз. И сохранить единство терминологии и последовательность изложения в тексте описания гораздо проще, если они основаны на законченной формуле изобретения.

Пункты 56-61 описывают требования к чертежам. В Правилах они сведены в одном подразделе, что упрощает их выполнение по сравнению с Регламентом, где они были разнесены по тексту. Следует также заметить, что в рекомендациях, действующих до 2008 года, были указания на следования основным положениям Единой системы конструкторской документации при составлении чертежей. В Правилах, по сути, от этого требования осталось положение, что "графические изображения выполняются черными нестираемыми четкими линиями одинаковой толщины по всей длине линии, без растушевки и раскрашивания". В результате при использовании компьютерных программ для создания чертежей выносные линии и штриховка (косые линии) часто становятся в три раза толще линий основных (а лучше было бы - наоборот). При этом основные линии при репродуцировании часто исчезают. Оптимальную толщину основных линий целесообразно делать в диапазоне 0,5-0,8 мм, а выносных и штриховку - в диапазоне 0,2-0,4 мм. Также ранее существовали рекомендации о нецелесообразности использования сборочных чертежей при подготовке графических материалов изобретений. Эти рекомендации были полезны, так как сборочные чертежи обычно содержат много подробностей, которые в чертежах заявок лучше не приводить, чтобы не перегружать их лишними подробностями. Идеальный вариант чертежей для заявки на получение патента такой, в котором изображены только те элементы, о которых идет речь в описании.

И, наконец, завершающий раздел Правил, относящийся к тексту заявки, п. 62 "Требования к реферату". В нем появилось существенное дополнение о том, что Реферат "не может быть использован для определения объема правовой охраны и внесения изменений в формулу изобретения". Дополнение уместное, так как многие изобретатели считают реферат наиболее важной частью заявки на изобретение, подходят наиболее ответственно к этому документу, излагают в нем наиболее важные отличительные признаки формулы изобретения (что верно), но иногда забывают это сделать в формуле и описании (что недопустимо).

И последнее, что следует отметить, какие бы правила оформления заявок не существовали, экспертиза имела и часто продолжает носить субъективный оттенок и в зависимости от конкретного эксперта, и в зависимости от конкретного отдела ФИПСа, в котором идет рассмотрение заявки. Например, я уже более десяти лет, особенно в сложных изобретениях с многозвенной формулой с большим количеством отличительных признаков, а также с большим количеством чертежей указываю номера позиций элементов конструкции в формуле изобретения, заключая их в круглые скобки. То же рекомендую делать и изобретателям. Если у вас количество элементов, упоминаемых в формуле и обозначенных на чертежах, приближается к сотне, то понять вашу формулу без ссылки на номера элементов бывает практически невозможно. Практику указания номеров элементов в формуле изобретения я позаимствовал из зарубежных патентов. В настоящее время многие зарубежные патентные поверенные без указания этих номеров у вас просто не возьмут материалы заявки в работу. Некоторые эксперты ФИПСа, понимая разумность этого шага, принимают такие формулы и оставляют номера позиций в конечных вариантах формулы. Тем не менее я до сих пор постоянно получаю требования некоторых экспертов об удалении указания позиций элементов устройства при характеристике его признаков. При этом, наиболее часто это обосновывается ссылкой на п. 53.11 вышеуказанных Правил, в котором, вообще говоря, никакого запрета на указание позиций элементов нет. Но эксперт считает, что если прямого требования указывать номера позиций в п. 53.11 не существует, то этих позиций в формуле и быть не должно, не смотря на очевидную от этого пользу. Это не единственный пример субъективной трактовки подготовки заявок.

Но закончить хочется на положительной ноте. Несмотря на "ужас", который начинающие изобретатели испытывают в процессе изучения Правил, не следует отказываться от попыток патентования своих решений. Большинство формальных ошибок, которые они допустят при подготовке заявок, можно будет устранить в процессе экспертизы, отвечая на запросы, не снимая заявки с рассмотрения.

\section{ЛИТЕРАТУРА}

1. Соколов Д.Ю. Работа с Административным регламентом по изобретениям: что посоветовать? // Патенты и лицензии. 2015. № 11. 